\begin{tabular}{|c|c|c|}
\hline $\begin{array}{l}\text { ISSN 2525-4812 (versão online) } \\
\text { ISSN 2238-7641 (versão impressa) } \\
\text { http://www.revistaterceiramargem.com/ } \\
\text { index.php/terceiramargem/index }\end{array}$ & $\begin{array}{c}\text { Recebido em: 230/8/2019 } \\
\text { Aprovado em: 12/2/2020 } \\
\text { Período de publicação: jan./jun., } 2020\end{array}$ & $\begin{array}{c}\text { Revista Terceira } \\
\text { Margem Amazônia } \\
(\text { v. } 6 \cdot \text { n. } 14 \cdot \text { Jan./Jun. } 2020)\end{array}$ \\
\hline
\end{tabular}

Como citar o artigo:

MATTOS, C. A. de S.; GELIO, M. M. P.; LIMA, R. O. de; ADDOR, F. Tecnologia social e reforma agrária: reflexões a partir do curso de formação crítica em sistemas de saneamento ecológico. Revista Terceira Margem Amazônia, v. 6, n. 14, p. 103-119, 2020. DOI: http://dx.doi.org/10.36882/2525-4812.2020v6i14p103-119

\title{
TECNOLOGIA SOCIAL E REFORMA AGRÁRIA: REFLEXÕES A PARTIR DO CURSO DE FORMAÇÃO CRÍTICA EM SISTEMAS DE SANEAMENTO ECOLÓGICO
}

\author{
Caroline Alves de Souto Mattos ${ }^{1}$ \\ Marcella Moraes Peregrino Gelio ${ }^{2}$ \\ Ruth Osorio de lima ${ }^{3}$ \\ Felipe Addor ${ }^{4}$
}

Resumo: Neste trabalho desenvolvemos uma análise sobre uma das ações do Projeto Tecnologia Social em Assentamentos da Reforma Agrária: o Curso de Formação Crítica em Sistemas de Saneamento Ecológico no Acampamento Edson Nogueira (Macaé, RJ), realizado pelo Núcleo de Solidariedade Técnica (Soltec/UFRJ). Desenvolvemos uma revisão bibliográfica com base em dois conceitos-chave do Projeto Tecnologia Social e Engenheiro Educador. O curso iniciou em 2018 e encontra-se em andamento, promovendo um processo de reflexão e prática sobre a questão do saneamento nos assentamentos e acampamentos da reforma agrária. A atuação foi analisada a partir de duas diretrizes da extensão universitária e apresenta-se como uma iniciativa que busca romper com a estrutura tecnológica convencional e aproximar a universidade das demandas dos movimentos sociais.

Palavras-chave: tecnologia social, extensão universitária, reforma agrária, saneamento ecológico.

\section{SOCIAL TECHNOLOGY AND AGRARIAN REFORM: REFLECTIONS FROM THE CRITICAL TRAINING COURSE IN ECOLOGICAL SANITATION SYSTEMS}

\begin{abstract}
In this work we analyse one of the actions of the Project Social Technology for Land Reform Settlements: the Extension Course in Critical Formation in Ecological Sanitation Systems at Edson Nogueira Camp (Macaé / RJ) organized by the Núcleo de Solidariedade Técnica (Soltec/UFRJ). We developed a bibliographic review on key concepts of the project: Social Technology and Engineer Educator. The

\footnotetext{
1 Graduanda em Engenharia Civil pela Universidade Federal do Rio de Janeiro (UFRJ), Núcleo de Solidariedade Técnica (Soltec/Nides/UFRJ), Rio de Janeiro, RJ. Email: c.soutomattos@gmail.com

2 Graduanda em Engenharia Civil pela Universidade Federal do Rio de Janeiro (UFRJ), Núcleo de Solidariedade Técnica (Soltec/Nides/UFRJ), Rio de Janeiro, RJ. Email: marcella.gelio@poli.ufrj.br

3 Graduanda em Engenharia Civil pela Universidade Federal do Rio de Janeiro (UFRJ), Núcleo de Solidariedade Técnica (Soltec/Nides/UFRJ), Rio de Janeiro, RJ. Email: osorio.ruth.b10@gmail.com

4 Engenheiro de produção, D. Sc. em Planejamento Urbano e Regional, pesquisador-extensionista do Núcleo de Solidariedade Técnica (Soltec/UFRJ), Rio de Janeiro, RJ. Email: felipe@nides.ufrj.br
} 
course began in 2018 and is underway with the prospect of promoting a process of reflection and practice on the issue of sanitation in settlements and agrarian reform camps. The extension project was analyzed from two university extension guidelines and can be seen as an initiative that seeks to break with the conventional technological structure and to bring the university closer to the demands of social movements.

Keywords: social technology, university extension, land reform, ecological sanitation.

\section{Introdução}

O projeto de extensão Tecnologia Social em Assentamentos da Reforma Agrária (TecSARA) é fruto da parceria entre o Núcleo de Solidariedade Técnica (Soltec/UFRJ), programa de extensão da Universidade Federal do Rio de Janeiro vinculado ao Núcleo Interdisciplinar para o Desenvolvimento Social (Nides/UFRJ), e o Movimento dos Trabalhadores Rurais Sem Terra no Rio de Janeiro (MST).

O Soltec/UFRJ surge em 2003 com a proposta de buscar maior integração entre ensino, pesquisa e extensão na engenharia, contribuindo para uma universidade que extrapole seus muros e se entenda como parte da sociedade. A partir de 2014, inicia-se uma parceria com o MST/RJ e, entre os anos de 2016 e 2017, seguindo uma demanda do MST, nasce o Projeto TecSARA.

No Brasil, a importância da agricultura familiar no abastecimento de alimentos é reconhecida pelos estudos do Censo Agrário de 2006 (IBGE, 2006), sendo um campo fundamental para o desenvolvimento rural (ABRAMOVAY, 2000). Ela é responsável por 70\% da produção de alimentos consumidos no Brasil, ocupando $84,4 \%$ do número total de estabelecimentos em apenas $24 \%$ da área total destinada à produção agropecuária.

Nesse contexto, entendemos a reforma agrária como um processo fundamental para a consolidação da agricultura familiar como estratégia de desenvolvimento no setor agropecuário, pois visa à reestruturação desse setor a partir da redistribuição fundiária, da assistência técnica e do acesso a crédito, apoiando a produção agrícola nos territórios assentados. No entanto, vemos que, frequentemente, essa produção é dificultada pela falta de estrutura nos assentamentos, comumente localizados em regiões mais afastadas, com escasso acesso a saúde, saneamento básico e soluções tecnológicas. O projeto apresentado neste trabalho busca contribuir para o atendimento de algumas dessas demandas.

Uma das bases metodológicas dessa relação com os assentados é a dialogicidade, buscando, portanto, não uma relação assistencialista e unilateral, mas um processo horizontal de troca de saberes e de formação crítica dos envolvidos, tanto dos acadêmicos quanto dos agricultores. Essa perspectiva, por um lado, dialoga com o conceito de tecnologia social (DAGNINO et al., 2004), cujo referencial metodológico valoriza a troca entre os saberes acadêmicos e empíricos dos trabalhadores, o uso de materiais disponíveis no ambiente onde está sendo desenvolvida a ferramenta, além da participação dos trabalhadores ao longo de todas as etapas de planejamento, construção e implementação da tecnologia, a fim de possibilitar os futuros processos de manutenção da solução tecnológica. Por outro lado, aproxima o projeto da perspectiva do Engenheiro Educador (FRAGA et al., 2011), buscando fomentar nos estudantes envolvidos maior capacidade de diálogo com os assentados, para que sejam capazes de perceber e valorizar os diferentes conhecimentos que se apresentam nos espaços coletivos do projeto. 
Neste artigo, faremos uma revisão bibliográfica sobre esses dois conceitos que orientam o projeto, apresentaremos a experiência, ainda em andamento, do Curso de Formação Crítica em Saneamento Ecológico e faremos uma análise buscando refletir sobre os avanços do projeto a partir de duas das diretrizes de extensão definidas pelo Fórum de Pró-Reitores de Extensão (Forproex): transformação social e impacto na formação do estudante. Como o projeto ainda está em curso, consideramos que essa é uma análise preliminar, que pode vir a contribuir para pensar os próximos passos do projeto.

\section{A Tecnologia Social e o Engenheiro Educador}

Ao pensar as relações existentes entre universidade e sociedade e, então, a comunicação em que elas se pautam, não é difícil observar que, frequentemente, o diálogo presumido se torna um monólogo. Isto é, em muitos casos, a universidade assume o papel de produzir o conhecimento, definir o que é científico ou não, o que é falso ou verdadeiro, e a sociedade externa simplesmente recebe essa informação. Nessa perspectiva, o conhecimento gerado na universidade acaba se tornando disciplinar e descontextualizado, ficando distante das demandas concretas da sociedade local.

Nesse cenário, a extensão pode ter um papel fundamental de aproximar as atividades de ensino e pesquisa da realidade que se encontra no entorno da universidade. Seguindo uma perspectiva dialógica e de compromisso com a transformação social e com a formação crítica dos estudantes, as ações extensionistas têm potencial de gerar maior vínculo entre as atividades acadêmicas realizadas dentro da universidade e as demandas reais dos trabalhadores daquela região. É buscando caminhar nessa direção que esse projeto se realiza.

Nesta seção, realizamos uma revisão bibliográfica trazendo dois conceitos, Tecnologia Social e Engenheiro Educador, que orientam metodologicamente o projeto de extensão apresentado, na busca pela transformação social e pelo impacto na formação do estudante.

\section{O campo da Tecnologia Social}

Marques (2011) destaca que a universidade propaga a crença de que existe universalidade e neutralidade na ciência. Nessa perspectiva, tudo o que a ciência produz se torna indiscutível e indubitável. Esse formato, construído no nosso modelo educacional e fixado epistemologicamente, cria raízes tão profundas e firmes que constrói no senso comum apenas uma ciência, neutra e messiânica, classificando saberes como científicos ou não. Assim, o científico recebe maior visibilidade e credibilidade, fazendo com que a ciência e tecnologia ganhem o prestígio de salvadoras da humanidade. Dessa forma, toda sociedade tem como objetivo chegar a um patamar de desenvolvimento alcançado pela inovação tecnológica.

O que não se explicita, nesse processo, é que a concepção de todo fato científico ou artefato tecnológico perpassa um processo de disputa territorial, política, social econômica e epistemológica. Consequentemente, não existe a construção puramente técnica de um artefato ou de um processo tecnológico a partir de uma ciência pura, uma vez que o estabelecimento de qualquer projeto requer decisões tomadas por pessoas, o que pode privilegiar uns e desfavorecer outros. No entanto, conforme reforça Marques (2011), ao se conceber uma tecnologia, toda a discussão 
política inerente à decisão técnica é apagada, e o artefato ou processo é consagrado pela coisa em si.

O modelo de difusão de tecnologia, pautado pela universalidade e neutralidade da ciência e tecnologia, reforça esse processo de invisibilização do social ao estabelecer o consenso de que existem formas certas para a construção de artefatos (MARQUES, 2011). As descobertas tecnológicas, por serem consideradas "certas", poderiam transferir-se para todos os lugares, sendo sua aplicação e eficácia dependentes exclusivamente do sistema em que estão. As tecnologias se estabelecem como coisas, em que todo o processo político para seu estabelecimento foi apagado, e sua aplicação é exigida ainda como coisa, e não como processo político.

A concepção e o desenvolvimento da ciência e tecnologia inseridos e afetados por um contexto social e cultural retrata, para este artigo, uma visão crítica que nos propomos a discutir. Nesse processo, o cientista é, além de pesquisador, um ator social que também reflete suas percepções, culturas e vivências. No entanto, entendemos que dentro e fora da universidade se carece de uma reflexão conceitual sobre a técnica. Os conceitos de ciência e tecnologia se tornam difusos e miscíveis e, ao pensar em seus campos associativos, sempre se encontram termos relativos à instrumentalização.

Segundo Álvaro Vieira Pinto (2005 apud HENRIQUES et al., 2015, p. 236), o referencial sobre tecnologia foi consolidado sobretudo após a Segunda Guerra Mundial e se caracteriza por duas visões distintas: a compreensão da tecnologia relacionada aos artefatos criados pelo ser humano e a concepção de "Era tecnológica", derivando uma lógica de patamar de desenvolvimento a ser alcançado e de transferência tecnológica; e, em sentido oposto, a ideia alarmista da tecnologia, que sugere o insucesso do homem diretamente associado a sua submissão à técnica.

O debate se enriquece com Renato Dagnino, para quem a tecnologia é representada pelo controle, "entendido como a habilidade relativa ao uso de conhecimento incorporado em artefatos tecnológicos" (2009 apud HENRIQUES et al., 2015, p. 238). Dagnino compreende a tecnologia como um produto da ação social que determinado ator tem sobre seu processo produtivo, que pode ter diferentes graus de apropriação a partir do contexto socioeconômico em questão.

Buscou-se desenvolver o curso de extensão, analisado neste artigo, a partir de uma perspectiva crítica da tecnologia, baseando-se principalmente na Teoria Crítica da Tecnologia, de Andrew Feenberg, que se funda na não neutralidade da tecnologia, no seu caráter parcialmente controlável e alarmista. Entendemos que o diferencial de Feenberg se dá pela contextualização que ele realiza em seu discurso, reforçando que, na sociedade moderna, a tecnologia pode determinar ou dificultar formas de vida de acordo com os interesses do capital. Assim, a sociedade capitalista torna a tecnologia utilitarista, pautada nos valores de produtividade, lucro e eficiência (2010 apud HENRIQUES et al., 2015).

Nesse contexto, Feenberg (2010 apud HENRIQUES et al., 2015) apresenta a racionalização subversiva ou democrática, objetivando ampliar a racionalidade e o controle sobre o processo de desenvolvimento tecnológico a partir da democratização do desenvolvimento e controle das tecnologias. Esse processo concebe uma nova idealização da tecnologia que vai além da concepção de lucro e produtividade, assumindo os diversos parâmetros envolvidos na construção da ciência e tecnologia. 
Com esse desafio de pensar uma outra forma de entender e fazer tecnologia, a partir das contribuições dos referidos e diversos atores e autores, emerge o que conhecemos hoje como tecnologia social (TS). Segundo Dagnino (2014, p. 144), TS é "resultado da ação de um coletivo de produtores sobre um processo de trabalho que, em função de um contexto socioeconômico (que engendra a propriedade coletiva dos meios de produção) e de um acordo social (que legitima o associativismo), os quais ensejam, no ambiente produtivo, um controle (autogestionário) e uma cooperação (de tipo voluntário e participativo), permite uma modificação no produto gerado passível de ser apropriada segundo a decisão do coletivo".

O conceito de TS se sustenta na crítica à neutralidade e universalidade da ciência e tecnologia consolidadas pela tecnologia convencional (TC). Por sua vez, a TC é caracterizada principalmente por: poupar mão de obra, focar na produção crescente, ser insustentável e intensiva de recursos, ser segmentada, hierarquizada e monopolizada (FRAGA et al., 2011).

Dessa forma, indo em oposição ao convencionado pela TC, entendemos a TS como um processo cujo objetivo se traduz principalmente em: firmar uma crítica ao modelo tradicional de desenvolvimento tecnológico, hierarquizado, centralizado; e propor uma dinâmica democrática, participativa, horizontal de intercâmbio de saberes e construção de soluções, promovendo um fortalecimento dos atores sociais.

\section{O engenheiro educador e a extensão}

Assimilando a discussão compreendida na concepção e desenvolvimento da ciência e tecnologia que o Projeto TecSARA se defrontou durante sua trajetória, começamos a perceber também a grande problemática relacionada à atuação e formação do engenheiro.

Alguns autores destacam como os cursos da área tecnológica e, particularmente, de Engenharia possuem uma perspectiva pouco reflexiva e crítica quanto ao processo de desenvolvimento ou de implantação da tecnologia. Em muitos casos, a formação do engenheiro remete a uma postura pouco dialógica, positivista, e que percebe sua atuação como algo puramente técnico, distanciado de questões sociais e culturais, como se houvesse uma racionalidade técnica superior que não pode e não deve ser afetada por questões político-ideológicas (DWEK, 2012; LIANZA et al., 2011). Entretanto, conforme argumenta Dagnino (2004 apud FRAGA et al., 2011), na sociedade capitalista, o engenheiro é o representante técnico do dono dos meios de produção já que ele se encarrega, baseado em parâmetros de eficiência e produtividade definidas por este, do controle dos meios de produção e, assim, dos trabalhadores, configurando uma situação de hierarquização de conduta e diálogo.

Pensar no engenheiro capaz de integralizar os conceitos de não neutralidade da ciência e tecnologia às suas práticas profissionais e reforçar com isso um novo fazer e pensar tecnologia na universidade e com os trabalhadores requer a atuação do engenheiro também como educador popular. Nesse sentido, o papel do engenheiro deixa de ser o de fornecer a solução tecnológica e passa a ser o de mediar os processos participativos que propiciarão um diagnóstico fidedigno da realidade e uma reflexão que resulte na proposição de soluções tecnológicas para os problemas identificados, em uma construção coletiva, retirando de si o foco como responsável pela solução e possibilitando a transição entre os saberes acadêmicos e populares (FRAGA et al., 2011). Por

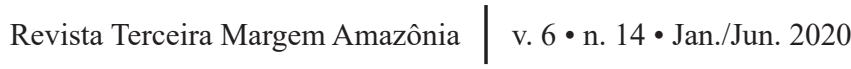


meio dessa transição, os trabalhadores podem transferir seus conhecimentos e valores para o processo tecnológico, assim como são capazes de conseguir, mediante processos educativos, falar na mesma linguagem dos engenheiros. Tendo em vista o conceito de Educação Popular relacionado à problematização e transformação da realidade com a visão crítica do trabalhador que possibilita sua atuação crítica, Fraga et al. (2011) identificam esse engenheiro como um "engenheiro educador".

Uma grande questão é que a formação tradicional em engenharia, com currículos majoritariamente voltados à formação técnica, não induz a percepção do engenheiro como educador. Em muitos casos, os estudantes de engenharia são ensinados a acreditar que seu exercício profissional se distancia completamente da prática da educação. Mesmo os engenheiros que trabalham na área da educação, frequentemente, não se preocupam com a reflexão das dinâmicas e com a didática do processo. No curso de Engenharia Ambiental da UFRJ, por exemplo, cursado por duas autoras deste artigo, seria esperado um destaque à questão da educação ambiental, já que se trata de um curso voltado para solução de problemas de engenharia dentro da problemática ambiental, sendo necessário, muitas vezes, o diálogo com a comunidade afetada pela respectiva questão ambiental. Entretanto, na realidade da UFRJ, a grade curricular não abrange esse tema e mesmo as disciplinas eletivas que se propõem a abordá-lo não o fazem de maneira crítica, ligada aos conceitos de educação popular e aos debates da ciência e tecnologia.

Nesse sentido, “é insuficiente discutir a atuação do engenheiro sem pensar em uma outra maneira de formar os engenheiros para essas demandas" (FRAGA et al., 2011, p. 19). Essa outra forma, muitas vezes, é encontrada pelos engenheiros por meio da extensão tecnológica popular, que permite o contato dos estudantes com uma realidade que demanda uma postura dialógica e uma prática horizontal, coletiva e cooperativa.

No contexto da ciência e tecnologia fundamentadas em uma perspectiva crítica, o processo de extensão, pautado nos princípios da TS, deve refletir a busca pela emancipação do sujeito social a partir da via de mão dupla que a universidade deve ser: o reconhecimento dos saberes múltiplos por meio da dialogicidade, interdisciplinaridade e indissociabilidade com o ensino e pesquisa. De acordo com o Fórum Nacional de Pró-Reitores de Extensão das Universidades Públicas Brasileiras (FORPROEX, 2012), a extensão na educação superior tem as seguintes diretrizes: "interação dialógica; formação cidadã dos estudantes; produção de mudanças na própria instituição superior e nos demais setores da sociedade; e a articulação entre ensino/extensão/ pesquisa, ancorada em processo pedagógico único, interdisciplinar, político educacional, cultural, científico e tecnológico". Dessa forma, observa-se que a extensão tem um objetivo duplo e inseparável: a transformação social e o impacto na formação do estudante.

Assim, o curso aqui analisado se baseia no princípio de que "educar e educar-se, na prática da liberdade, não é estender algo desde a "sede do saber", até a "sede da ignorância" para "salvar", com este saber, os que habitam nesta" (FREIRE, 1983, p. 15). Na prática, se afirmando sob uma ótica de uma engenharia não hegemônica e, sobretudo, anticapitalista, e pensando na atuação do engenheiro educador, o Curso de Formação Crítica em Saneamento Ecológico se apoiou nos princípios metodológicos da pesquisa-ação (PA) (ADDOR; ALVEAR, 2015) e da educação popular (EP) (FREIRE, 1983), buscando, assim, a construção coletiva do conhecimento emancipatório. 
Nesse sentido, além da discussão crítica sobre a transmissão do conhecimento e a desconstrução da ciência universal, a participação dos atores sociais e a práxis são elementos-chaves para a avaliação do desenvolvimento do Projeto TecSARA. Isto é, a relação entre os pesquisadores/ extensionistas busca ir para além de uma relação entre sujeito e objeto, constituindo-se como uma participação autêntica em que ambos os atores se reconhecem como seres reflexivos e se pautam na confiança e no respeito mútuo. A práxis, consistindo na reflexão + ação + reflexão e se relacionando justamente ao fato de que o conhecimento não deve ser descolado da realidade, direciona o curso a buscar as discussões dos problemas a partir da prática.

\section{O Curso de Formação Crítica em Saneamento Ecológico}

O Projeto Tecnologia Social em Assentamentos da Reforma Agrária (TecSARA) foi desenvolvido a partir da parceria, já existente, entre o Projeto Campo-Cidade: Fortalecendo Coletivos de Produção da Reforma Agrária (CaCi), também do Núcleo de Solidariedade Técnica (Soltec/ UFRJ), e o MST-RJ. O TecSARA surge a partir da demanda do movimento devido às condições precárias de infraestrutura nos assentamentos e acampamentos do estado do Rio de Janeiro.

Esse diálogo iniciou-se em 2014, quando o movimento entrou em contato com o núcleo solicitando assessoria à Cooperativa de Produtos Agroecológicos Terra Fértil (Coopaterra), em Duque de Caxias. Após um período de conhecimento e visitas nos espaços, em 2015, foi realizado um diagnóstico participativo sobre a cooperativa, cuja análise resultou em um curso de extensão curto (seis encontros com um total de 36 horas) com foco em duas das principais demandas apresentadas pela cooperativa: Gestão Financeira e Planejamento e Controle da Produção. O êxito dessa primeira experiência levou à proposição de um novo curso voltado a diferentes coletivos de produção de assentamentos de todo o estado do Rio de Janeiro, ao longo de 2016 e 2017, dessa vez com maior duração (sete módulos com um total de 146 horas), denominado Gestão e Cooperação Agroecológica (GCA) .

Foi nesse mesmo período que se iniciou o diálogo sobre a demanda que levaria à criação do TecSARA (2016) e que se realizou sua primeira atividade (2017): o curso de Formação Crítica em Sistemas Técnicos de Energia, no Assentamento Irmã Dorothy (Quatis/RJ) ${ }^{6}$. Esse curso permitiu iniciar uma reflexão metodológica sobre como trabalhar com as questões tecnológicas de infraestrutura nesses territórios, promovendo espaços de diagnóstico participativo e de intercâmbio de conhecimentos para se pensar possíveis soluções tecnológicas, considerando tanto o saber e a experiência dos agricultores quanto as técnicas e conhecimento científico dos acadêmicos. Baseado nos conceitos da TS e da EP, e na visão do engenheiro educador, essa primeira experiência foi chave para se construir a proposta do curso analisado neste artigo.

Em seguida, aprofundamos como se deu o percurso formativo da equipe e a atuação extensionista mais recente do TecSARA: o curso de formação crítica em Saneamento Ecológico no Acampamento Edson Nogueira (Macaé, RJ).

\footnotetext{
Mais detalhes sobre o curso Gestão e Cooperação Agroecológica em Oliveira Filho e Laricchia (2018).

6 Mais detalhes sobre o curso de energia em Franco e Andrés (2018).
} 


\section{Formação dos extensionistas}

A partir da perspectiva do engenheiro educador (FRAGA et al., 2011), entendemos que a criação de um espaço de formação inicial dos estudantes seria fundamental para fazer com que estes construíssem juntos o conhecimento sobre os temas centrais do projeto e pudessem partir de bases semelhantes para a atuação no campo. Isso porque, como discutido, a formação tradicional em engenharia não fornece, em geral, uma base metodológica de diálogo com os trabalhadores nem propõe uma reflexão sobre sua prática. Portanto, era colocado o desafio: como levar extensionistas ensinados a partir de um modelo de difusão tecnológica e de neutralidade da ciência e tecnologia a interagirem com espaços em que esses processos são vistos a partir de outra perspectiva?

Nesse sentido, a equipe passou por um percurso formativo no primeiro semestre de 2018, reproduzido em 2019 com a chegada de novos membros. Mesmo entendendo que a práxis parte do princípio de que a formação e atuação no campo se dão no mesmo sentido, achamos importante esse espaço inicial de formação dentro da universidade para que os extensionistas absorvessem uma bagagem para o diálogo com o movimento e seus trabalhadores a partir da Teoria Crítica da Tecnologia.

Inicialmente, o Soltec/UFRJ realizou um curso de formação dentro da UFRJ, mas não restrito apenas aos seus membros, denominado Extensão, Tecnologia e Participação, como forma de seleção de novos integrantes e com o propósito de apresentar aos futuros membros do núcleo as referências teóricas e metodológicas que estruturam sua prática. Dessa forma, os projetos CaCi e TecSARA receberam oito estudantes de diferentes cursos de graduação: Engenharia Ambiental, Engenharia Elétrica, Engenharia Civil, Ciências Sociais, Física, Engenharia Eletrônica e Computação e Administração.

Como os projetos possuem temas afins e uma trajetória aproximada, decidimos que seria uma formação conjunta feita em encontros semanais, onde se faria a discussão de um texto visando aprofundar os temas tratados no curso de formação, como educação popular, pesquisa-ação e reforma agrária. Além dos textos, utilizamos materiais audiovisuais e visitas aos espaços do MST como ferramentas pedagógicas desse processo formativo.

Outra atividade importante para a formação dos estudantes foi a organização da V e VI Jornada Universitária em Defesa da Reforma Agrária (Jura). A Jura tem como objetivo ampliar e resgatar, no âmbito universitário, o debate sobre a importância da reforma agrária popular, da luta pela terra, por educação popular no campo e por uma alimentação saudável, livre de transgênicos e agrotóxicos. Nesse sentido, os estudantes organizaram, em 2018 e 2019, diversas atividades da Jura no centro de tecnologia (CT/UFRJ), com o intuito de sensibilizar a comunidade acadêmica.

Trazer essa discussão a partir de uma perspectiva tecnológica contribui em muito para que os estudantes percebam a complexidade que há nos processos de desenvolvimento tecnológico, e como as tomadas de decisão tecnológica estão embebidas de posições políticas, econômicas e sociais que serão vistas nos impactos que essas tecnologias terão. Mesas realizadas com temas como "O que você sustenta quando se alimenta?" ou "O que a tecnologia tem a ver com a Reforma Agrária" contribuíram muito para que a discussão da não neutralidade da tecnologia 
saísse de um plano teórico para uma abordagem concreta, visto tanto do ponto de vista dos acadêmicos quanto dos próprios agricultores.

Após esse processo inicial de formação da equipe do projeto, iniciamos o trabalho de organização do curso de extensão.

\section{Curso de Formação Crítica em Saneamento Ecológico}

A partir das avaliações do curso de energia, a equipe extensionista, em conjunto com a organização do movimento, decidiu por continuar a parceria desenvolvendo outro curso na área tecnológica. O local escolhido para o curso foi a Unidade Pedagógica de Agroecologia Marielle Franco, localizada no acampamento Edson Nogueira, em Macaé, RJ, onde cerca de 50 famílias ocupam e viabilizam a construção do projeto pedagógico da unidade, projeto aprovado na Câmara Municipal de Macaé com o apoio do Edital de Assistência Técnica em Habitação Social do Conselho de Arquitetura e Urbanismo do Rio de Janeiro (CAU-RJ).

Partindo da premissa da construção dialógica que orienta as perspectivas da EP e da TS, alguns acordos do curso foram construídos previamente com o MST e a coordenação local do assentamento, onde definiu-se, por razões estruturais e organizacionais, que o curso seria inserido como atividade da unidade pedagógica, sendo realizado no espaço do acampamento Edson Nogueira; o tema a ser trabalhado seria saneamento básico, por ser uma temática de maior urgência nesse contexto; a definição de um protótipo pedagógico e funcional ocorreria dentro do curso e estaria sujeito à limitação orçamentária do projeto; o cronograma contaria com cinco visitas no total, no segundo semestre de 2018; o mutirão de implementação seria diluído, ao invés de uma visita específica para tal; o acompanhamento seria pela direção regional do movimento; haveria também a participação de assentados do assentamento Osvaldo de Oliveira, localizado no município de Macaé, RJ.

Inicialmente, o conteúdo programático foi pensado a partir do escopo de um projeto de saneamento rural - levantamento de demanda; escolha da solução técnica; dimensionamento; e implementação - acompanhado de discussões visando à problematização dos elementos envolvidos no processo de desenvolvimento técnico. Acreditamos que esse modelo, quando feito de maneira participativa, enfatiza o potencial da tecnologia de promover uma reflexão sobre o nosso ser e estar no mundo; segue a racionalização subversiva proposta por Feenberg (2010 apud HENRIQUES et al., 2015), já que proporciona o controle sobre o desenvolvimento tecnológico; e também trabalha a característica da tecnologia de ser política e local.

Esse processo permite evitar o equívoco muito comum em assessorias técnicas na área rural, quando soluções tecnológicas externas, desvinculadas da realidade local e sem terem sido apropriadas pelos trabalhadores locais, são implantadas para pouco tempo depois serem abandonadas. Na própria região de Macaé, há esse histórico de casas de farinha que foram instaladas há algumas décadas pelo governo local, mas que não tinham sido implantadas a partir de diálogo e do fortalecimento de um tecido social.

Devido a problemas burocráticos, orçamentários e de agenda política foram realizadas apenas duas visitas em 2018. Em uma primeira visita de reconhecimento, houve discussão da 
proposta do curso, reflexão sobre parâmetros importantes para a escolha técnica a partir das condições físicas/locais do acampamento e conversa sobre implicações e subjetividades envolvendo tal escolha. Na segunda, ocorreu uma discussão mais aprofundada sobre os elementos envolvidos ou que tangenciam a questão do saneamento, ainda sem entrar nos "mutirões pedagógicos". Os temas identificados para a discussão crítica foram: o acesso à água; os atores e interesses envolvidos no saneamento básico macaense e brasileiro; os usos da água no acampamento; mediações técnicas e desenvolvimento técnico; saúde no campo e saneamento rural; e questões de gênero.

Esses espaços permitiram uma discussão mais detalhada com os agricultores e a coordenação do movimento sobre quais eram os parâmetros prioritários para se tomar a decisão do protótipo a ser construído. Questões como a contribuição para sua organização e permanência no acampamento e o uso da matéria-prima local (no caso, o bambu) foram fundamentais para direcionar para a melhor solução tecnológica para aquele contexto.

Infelizmente, a restrição no número de visitas, por questões orçamentárias e de agenda, e a demanda institucional, por definir os materiais a serem comprados, obrigaram a equipe do projeto a tomar a decisão final sobre essa solução. Esse fato, cremos, que ressalta a dificuldade de se propor um projeto com base na TS a partir de uma estrutura institucional que não tem a cultura de fortalecer processos participativos e cujas exigências burocráticas acabam interferindo no que seria o ideal metodológico do projeto. Entretanto, apesar disso, acreditamos que os espaços de troca de informação e discussão anteriores permitiram um avanço interessante dos dois lados, tanto dos trabalhadores, no sentido de ver os problemas de saneamento e nas possibilidades de solução, quanto dos extensionistas em sua capacidade de enxergar aquela realidade a partir da visão dos moradores locais.

A escolha do protótipo, baseada no levantamento de demanda, foi um "banheiro seco bason" para os núcleos familiares e um sistema para a cozinha coletiva envolvendo uma caixa de gordura ecológica associada a uma "zona de raízes" ou "zona de alagados construídos" e um círculo de bananeiras. O sistema consiste em etapas de tratamento e destinação final de águas cinzas, com posterior infiltração no solo. Dessa forma, os efluentes da pia, que antes iam direto para um sumidouro e contaminavam o solo, servem como insumo para o crescimento das plantas no local.

Cabe ressaltar que a solução do problema técnico por si só já é muito importante, visto que a ausência de esgotamento sanitário dentro de um acampamento afeta não só a produção de alimentos e a salubridade, mas também passa por uma decisão política de ter um acampamento "ecologicamente correto". No entanto, essa tecnologia só pôde ser considerada no diálogo com os acampados em função de sua potencialidade para fomentar uma construção coletiva e de apropriação pelos trabalhadores, seguindo a perspectiva da TS.

Nesse processo, o papel dos extensionistas do TecSARA, partindo de uma perspectiva do engenheiro educador, foi o de mediar os encontros, apresentar as propostas conhecidas pelo grupo dentro do saneamento ecológico, conduzir o tema para sua discussão social e política, facilitando, assim, a reflexão sobre o pensar fazer tecnológico. Foi fundamental a formação anterior que per-

\footnotetext{
Mais informações sobre a tecnologia: http://www.ecoeficientes.com.br/o-que-e-o-bason/.

8 Mais informações sobre a tecnologia: http://www.fec.unicamp.br/ saneamentorural/index.php/tecnologias/
} 
mitiu que os estudantes tivessem uma postura de escuta e de busca da compreensão da realidade local, fundamentais para um projeto de extensão tecnológica que se baseia nos princípios da TS.

Em 2019, a partir de um financiamento coletivo organizado pela equipe do projeto foi possível fazer o trabalho de mutirão junto com os trabalhadores para a implantação da caixa de gordura e "zona de raízes", previstas como protótipo pedagógico funcional do curso. Vale destacar que o uso pedagógico da construção de um protótipo inserido em um processo de formação mais amplo havia sido uma estratégia do primeiro curso do TecSARA, com foco em energia, e se mostrou uma ferramenta interessante de fomento ao trabalho coletivo, organização da gestão comunitária e de apropriação dos conhecimentos técnicos utilizados no protótipo.

A consolidação da Unidade Pedagógica de Agroecologia, ocorrida ao longo do projeto, resultou em outros espaços, organizados com outros parceiros do movimento, que trouxeram a discussão sobre metodologias de educação popular, estando em pleno diálogo com a proposta dialógica e horizontal que o TecSARA propõe. Dessa forma, a equipe optou por acompanhar algumas dessas atividades, buscando entender as novas dinâmicas do acampamento e como se dava a estrutura das aulas para, então, repensar os próximos passos do curso de saneamento.

Assim, a continuidade do curso se deu a partir de uma aula pública proposta pela equipe e incorporada à unidade pedagógica, denominada "Ecossaneamento, cuidados com a água e o agroecossistema: instalação da caixa de gordura e zona de raízes", e contou com a participação de cerca de 40 pessoas, entre trabalhadores, trabalhadoras e estudantes de universidades parceiras e foi realizada em um final de semana. No primeiro dia, ocorreu a apresentação teórica sobre o tema, resgatando as discussões feitas em 2018, além de um mutirão inicial de preparação da área da cozinha coletiva. No segundo dia, houve o "mutirão pedagógico" de construção do sistema de tratamento da cozinha a partir do trabalho coletivo entre educandos e educadores.

Houve um terceiro dia para a finalização do sistema e avaliação da atividade com os trabalhadores e a coordenação local. Vale ressaltar que o formato da atividade em mutirões pedagógicos permitiu uma aproximação prática do que discutimos como democratização do desenvolvimento tecnológico e controle da tecnologia pelos atores sociais, pois proporcionou o diálogo horizontal entre os diferentes saberes ao longo da construção do sistema e suas respectivas tomadas de decisão.

Como forma de avaliação do processo, ainda em andamento, foram realizados três espaços diferentes: reuniões ao final de cada visita para avaliação com os trabalhadores; uma reunião de avaliação com a direção do movimento, diante da problemática orçamentária do projeto e da conjuntura política em que a unidade se encontrava no final de 2018; e reuniões de avaliação internas, visando analisar as mudanças metodológicas e desenvolver alternativas para a viabilização de recursos.

A perspectiva atual é que o curso seja retomado no primeiro semestre de 2020, tendo como perspectiva a construção do "banheiro seco bason" e a continuidade da discussão crítica acerca dos temas que ainda não foram abordados. Também vem sendo construída uma proposta de parceria com o Laboratório Interdisciplinar de Tecnologia Social (LITS/UFRJ-Macaé), situado no 
campus da UFRJ em Macaé, que vem desenvolvendo o projeto de uma casa de farinha no assentamento Osvaldo de Oliveira e que tem a demanda de um projeto de saneamento ecológico para esse equipamento, também com a perspectiva da TS.

\section{Reflexões a Partir da Experiência Extensionista}

A experiência do projeto de extensão do TecSARA vem contribuindo para as reflexões teórico-metodológicas sobre nossa atuação enquanto universidade. Buscamos recorrentemente fazer um processo de avaliação de acordo com as bases que orientam nossa atuação: TS e Engenheiro Educador. Consideramos que ambas as perspectivas têm como questão central contribuir para os dois objetivos centrais da atuação extensionista: a transformação social e o impacto na formação do estudante. Assim, trazemos uma reflexão, em construção, sobre em que sentido o projeto tem conseguido contribuir nesses dois objetivos, tendo por base o referencial apresentado neste artigo.

\section{Transformação Social}

Entendendo a transformação social a partir do marco teórico da TS com uma abordagem metodológica da educação popular e pesquisa-ação, observamos que a transformação da realidade se estrutura principalmente a partir da busca pela emancipação dos atores locais; isto é, quando o trabalhador se reconhece na sua realidade e consegue agir criticamente sobre ela. Dessa forma, usamos a práxis e a participação como parâmetros de análise dessa transformação, discutindo as potencialidades e limitações do projeto.

Visando estimular a reflexão na prática técnica, a equipe buscou, a partir da observação e das discussões nas visitas, identificar: a demanda técnica no contexto da luta pela reforma agrária; a relação com outras problemáticas; e os elementos do desenho e implementação do protótipo pedagógico que pudessem problematizar a relação dos acampados com as técnicas de saneamento. Essa busca fez-se necessária por não existirem estudos dessas demandas ou sobre as técnicas possíveis para o protótipo a partir da perspectiva crítica descrita no marco teórico. Um dos resultados desse processo foi o surgimento da relação entre as demandas técnicas do acampamento com a saúde e produção de alimentos.

Acreditamos que a perspectiva da TS apresenta um diferencial por estimular, ao longo do processo, maior formação técnica e política dos envolvidos, como foi possível identificar neste projeto. A participação dos agricultores no debate sobre os parâmetros relevantes para a definição da melhor técnica para saneamento representou uma formação relevante que não haveria acontecido em um processo tecnológico tradicional, em que os engenheiros fariam o diagnóstico e implantariam o equipamento sem o diálogo e a escuta da realidade dos moradores. Além disso, o estímulo ao trabalho coletivo e cooperativo realizado pelo projeto nos pareceu importante para que os agricultores se apropriassem da tecnologia e para que tivessem maior comprometimento na sua manutenção em longo prazo.

É importante destacarmos que, na concepção da equipe do projeto, o principal espaço de reflexão seria a própria construção do protótipo, ainda que os momentos de discussão teórica tenham ampliado a perspectiva dos trabalhadores. Esse fator, somado a uma preferência dos trabalhadores pela ação prática, fez com que os elementos problematizadores não fossem tão apro- 
fundados quanto o planejado. Acreditamos ainda ser um desafio metodológico conseguir fazer uma formação teórica qualificada, considerando a cultura de pôr as mãos na massa, presente nos trabalhadores do campo.

Considerando a distribuição espacial mais compacta de um acampamento e, ainda, o fato deste ser compreendido pelo movimento como um momento de quebra de paradigmas quanto à coletivização do trabalho (FIGUEIREDO; PINTO, 2014), alguns pontos devem ser ressaltados quanto à participação e mobilização dos trabalhadores ao longo das atividades.

No âmbito da participação, desde a apresentação da proposta até os momentos avaliativos, houve a presença da coordenação local e dos acampados. A partir das reuniões de elaboração da proposta, as principais definições sobre os objetivos e responsabilidades de cada parte (acampados, direção e equipe extensionista) foram construídas coletivamente. Os momentos avaliativos, por sua vez, foram realizados em plenária ao final de cada visita, de forma a valorizar os instrumentos de organização coletiva e estimular a participação, tanto da coordenação quanto dos acampados, no reconhecimento dos elementos mais importantes do processo. Esse fator trouxe um caráter mais democrático quanto à definição dos rumos do curso de saneamento, levando-se em consideração, também, as tomadas de decisão em cima das dificuldades orçamentárias do projeto e de contexto político do acampamento.

Em relação à mobilização, a proposta pedagógica do acampamento Edson Nogueira facilitou o comprometimento coletivo dos trabalhadores com as atividades do curso. Nesse sentido, o desenvolvimento de outras atividades dentro da programação da unidade pedagógica fez surgir uma regularidade na formação e mobilização coletiva. Por outro lado, o dinamismo "natural" de um acampamento faz com que a frequência das pessoas em todas as atividades seja deficitária, sendo necessária a retrospectiva dos elementos abordados em visitas passadas. Além disso, a questão de gênero, assim como nas experiências anteriores, segue como uma problemática a ser trabalhada em futuras atuações, visto que a participação das mulheres nas atividades do curso foi afetada pelo preparo das refeições coletivas.

A partir de uma perspectiva mais concreta, também vale destacar o êxito da implantação de um sistema de saneamento ecológico para a cozinha comunitária que vai permitir que seu uso gere menos impactos ambientais no assentamento. Além disso, considerando que todo seu processo de construção foi feito de forma participativa e por meio de mutirões, essa implantação pode servir de estímulo para que essa tecnologia seja reaplicada em outros assentamentos e acampamentos, principalmente os ligados ao MST. Essa possibilidade de reaplicação só existe em função da metodologia de construção e apropriação coletiva do conhecimento proposta pela TS, permitindo que os próprios agricultores sejam capazes de construir novas soluções semelhantes a partir do aprendizado do curso; o que, novamente, não seria possível em um processo de assessoria tecnológica convencional, sem a troca de saberes e a apropriação tecnológica.

\section{Impacto na formação do estudante}

Sendo o TecSARA um projeto de extensão universitária, ele está sujeito às diretrizes estabelecidas pela Pró-Reitoria de Extensão da UFRJ (PR5). Com as formalidades inerentes a essa institucionalização é necessário que a equipe executora seja coordenada formalmente por 
um professor ou técnico administrativo da UFRJ, reforçando uma lógica hierárquica dentro da instituição.

Entretanto, o projeto é caracterizado por um forte protagonismo dos graduandos e mestrandos e um espaço democrático e horizontal de tomada de decisão. Isso se deve, em parte, ao percurso formativo desses estudantes, que acabam conquistando mais autonomia com o autorreconhecimento como agente político, mas também ao fato de que, na área tecnológica, não é trivial achar professores ou técnicos interessados em coordenar um projeto de extensão tecnológica em parceria com movimentos sociais, o que faz com que os alunos sejam protagonistas em todas as etapas de desenvolvimento do projeto.

Dessa forma, a autonomia dos estudantes é extremamente valorizada no projeto, já que possibilita: o contato direto com os representantes dos movimentos; liberdade e franqueza na comunicação; autossuficiência para buscar referências, novas perspectivas e formas de avaliação; capacidade de autogestão. Essa diversidade de atuação, que vai muito além da simples aplicação de conhecimentos técnicos previamente obtidos, representa um espaço de formação importante, ampliando a capacidade de diálogo desses jovens nos diferentes contextos do projeto. Entretanto, a falta de maior presença de servidores da universidade também se constitui em empecilho para a equipe, pois há questões burocráticas internas e questões políticas externas que demandam o envolvimento de um professor ou um técnico-administrativo.

Outra questão crucial para pensar a atuação dos estudantes é a formação tradicional em engenharia. Como discutido anteriormente, a forma convencional de educação em engenharia não se adequa aos princípios da educação popular. Ao mesmo tempo, os processos de transformação social geralmente carecem de profissionais do campo tecnológico. Nessas circunstâncias, os estudantes de engenharia se deparam com dificuldades enraizadas na tentativa de aproximar a prática de atuação junto aos acampados dos estudos teóricos sobre ciência, tecnologia e sociedade, pois, por mais que saibam que prática e teoria não se separam, é difícil buscar referências e orientações no cotidiano da universidade que aproximem o engenheiro do papel de educador que se faz necessário na atuação extensionista.

O processo de formação da equipe do projeto, descrito anteriormente, tem papel importante de introduzir a reflexão sobre outra forma de fazer e pensar engenharia. Entendemos que, sem esse processo, toda a formação do curso de extensão seria impossibilitada, pois careceríamos de uma reflexão sobre a técnica, e, provavelmente, a chance de reproduzirmos no campo os ideais positivistas e hierárquicos do campo tecnológico seria muito maior. No entanto, ainda é necessário ter grande cuidado para que a técnica em questão seja de fácil assimilação e sirva de ponte para outras discussões problematizadoras da realidade. Mesmo no contexto da extensão e com o percurso formativo dos estudantes, encontrar esse cuidado não é um trabalho corriqueiro e demanda grande estímulo de busca do estudante.

O cenário do acampamento também é um amplo item de questionamento quanto aos seus impactos na formação do estudante, já que, no geral, se trata de uma realidade bastante diferenciada da usual dos estudantes. $\mathrm{O}$ confronto com essa realidade trouxe, principalmente, o debate de gênero para dentro da equipe, considerando que as mulheres são encarregadas de cuidar da alimentação de todos os participantes durante o curso, e o envolvimento dos homens neste momento 
é quase nulo, o que é uma prática comum do cotidiano do acampamento. Além das reflexões teóricas desse debate, como o papel da mulher no campo, a situação da mulher na sociedade e nos movimentos sociais, sobretudo no MST, uma grande questão para o grupo foi a nossa insuficiência de atuação perante essa situação.

A base metodológica da TS e a vivência dos estudantes de engenharia com trabalhadores vinculados a um movimento social permitiram um avanço interessante no sentido de propiciar espaços horizontais de intercâmbio de saberes. Pelo fato de os agricultores estarem vinculados a um movimento social e possuírem uma formação política anterior, com práticas cooperativas e autogestionárias, os estudantes tiveram que assumir sua perspectiva de engenheiro educador, chegando ao território não como detentores do saber e conhecedores das melhores soluções, mas como facilitadores de um processo coletivo de diagnóstico, debate e tomada de decisão que não se vivencia normalmente no âmbito acadêmico.

O fato de o processo ter ocorrido sem maiores conflitos e com retorno satisfatório do MST e dos agricultores nos parece um indicador de que a formação prévia dos estudantes teve impacto positivo para que eles assumissem essa postura defendida pela perspectiva teórico-metodológica da TS.

\section{Considerações Finais}

Apesar de alguns problemas enfrentados durante a trajetória do TecSARA, entende-se que o projeto, mesmo que ainda caminhando para alcançar seus objetivos, conseguiu dar uma contribuição no que diz respeito à formação crítica dos envolvidos e à parceria criada entre a instituição e os movimentos sociais. O projeto proporcionou aos estudantes a vivência em um acampamento, criando uma relação de confiança, que facilita o trabalho conjunto e solidário, algo imprescindível no campo da TS. Além disso propiciou a esses jovens vivenciarem um processo de desenvolvimento tecnológico muito diferente do que costumam ver em laboratórios ou empresas, a partir de uma perspectiva coletiva, comunitária, de valorização do saber popular.

Outro ponto positivo foi a interdisciplinaridade, principalmente no momento de formação dos extensionistas, com discussão de textos com a presença de alunos de diversas áreas, o que foi fundamental para que fossem apresentados diferentes pontos de vista sobre um mesmo assunto. Até aqui, referiu-se aos estudantes de engenharia como um todo; entretanto, no momento em que se fala de interdisciplinaridade, vale ressaltar que estavam envolvidos diferentes núcleos de engenharia, o que foi um ponto relevante na escolha dos cursos oferecidos.

A transformação da educação no campo tecnológico ainda é um desafio de longo prazo. A extensão tecnológica baseada nos princípios da tecnologia social e do engenheiro educador parece uma ferramenta importante para a formação de engenheiros que tenham maior comprometimento com as demandas da maioria da população brasileira e que tenham a capacidade de estabelecer um espaço de diálogo com os trabalhadores de diferentes áreas. Criar esses espaços horizontais e coletivos é que exige um perfil educador que não é desenvolvido nos cursos de engenharia no Brasil. 
Acreditamos que o trabalho extensionista com os movimentos sociais contribui para que o objetivo de preparar os estudantes possa ser articulado com uma perspectiva concreta de transformação social, fazendo com que a atuação no campo possa ter impactos de longo prazo e possa trazer frutos para além daquele trabalho específico e daquele território determinado.

\section{Referências}

ABRAMOVAY, R. O capital social dos territórios: repensando o desenvolvimento rural. Economia Aplicada, v. 4, n. 2, p. 379-397, abr./jun. 2000.

ADDOR, F.; ALVEAR, C. A. S. de. Sobre o conceito e a prática da pesquisa-ação. In: ADDOR, F.; HENRIQUES, F. C. (Org.). Tecnologia, participação e território: reflexões a partir da prática extensionista. Rio de Janeiro: Editora UFRJ, 2015. p. 119-145. Disponível em: http://nides.ufrj.br/images/ Imagens/programas/SOLTEC/Soltec_3-Tecnologia_participacao_e_territorio_baixaRes.pdf. Acesso em: 25 ago. 2019.

DAGNINO, R. Tecnologia social: contribuições conceituais e metodológicas. Campina Grande: EDUEPB, 2014.

DAGNINO, R.; BRANDÃO, F. C.; NOVAES, H. T. Sobre o marco analítico-conceitual da tecnologia social. In: TECNOLOGIA social: uma estratégia para o desenvolvimento. Rio de Janeiro: Fundação Banco do Brasil, 2004. 216 p.

DWEK, M. Por uma renovação da formação em engenharia: questões pedagógicas e curriculares do atual modelo brasileiro de educação em engenharia. 2012. 135 f. Dissertação (Mestrado em Engenharia de Produção) - Universidade Federal do Rio de Janeiro, Rio de Janeiro.

FIGUEIREDO, G. C.; PINTO, J. M. de R. Acampamento e assentamento: participação, experiência e vivência em dois momentos da luta pela terra. Psicologia \& Sociedade, v. 26, n. 3, p. 562-571, Dec. 2014. Disponível em: http:/www.scielo.br/scielo.php?script=sci_arttext\&pid=S0102-71822014000300005\& lng=em \&nrm=iso. Acesso em: 31 ago. 2019.

FÓRUM DE PRÓ-REITORES DE EXTENSÃO DAS INSTITUIÇÕES PÚBLICAS DE EDUCAÇÃO SUPERIOR BRASILEIRAS - FORPROEX. Política Nacional de Extensão Universitária. Porto Alegre: Gráfica da UFRGS, 2012. (Coleção Extensão Universitária, 1).

FRAGA, L.; SILVEIRA, R.; VASCONCELLOS, B. O engenheiro educador. In: SCHMIDT, C.; NOVAES, H. T. Economia solidária e mudança social. Porto Alegre: UFRGS, 2011. Disponível em: http://www. itcp.unicamp.br/drupal/files/eng\%20educador.pdf. Acesso em: 31 ago. 2019.

FRANCO, R.; ANDRÉS, N. Contribuições da educação popular e da pesquisa ação à adequação sociotécnica: estudo de caso de um curso de extensão. 2018. 144 f. Dissertação (Mestrado Profissional em Tecnologia para o Desenvolvimento Social) - Universidade Federal do Rio de Janeiro, Rio de Janeiro. Disponível em: http://nides.ufrj.br/images/PPGTDS/Dissertacoes/2018_NelsonRavelo.pdf. Acesso em: 31 ago. 2019.

FREIRE, P. Extensão ou comunicação. 7. ed. Rio de Janeiro: Paz e Terra, 1983.

HENRIQUES, F. C.; NEPOMUCENO, V.; ALVEAR, C. A. S. de. O conceito de tecnologia: reflexões para a prática da extensão universitária na área tecnológica. In: ADDOR, F.; HENRIQUES, F. C. (Org.). Tecnologia, participação e território: reflexões a partir da prática extensionista. Rio de Janeiro: Editora UFRJ, 2015. p. 235-258. Disponível em: http://nides.ufrj.br/images/Imagens/programas/SOLTEC/ Soltec_3-ecnologia_participacao_e_territorio_baixaRes.pdf. Acesso em: 25 ago. 2019. 
IBGE. Censo Agropecuário 2006. Agricultura familiar - Brasil, grandes regiões e unidades da federação. Primeiros resultados. Disponível em: www.ibge.gov.br/home/estatistica/economia /agropecuaria/censoagro/agri_familiar_2006_2/default.shtm. Acesso em: 25 ago. 2019.

LIANZA, S.; ADDOR, F.; CARVALHO, V. Solidariedade técnica: por uma formação crítica no desenvolvimento tecnológico. In: LIANZA, S.; ADDOR, F. (Org.). Tecnologia e desenvolvimento social e solidário. 1. ed. atual. Porto Alegre: Editora da UFRGS, 2011. p. 31-45. Disponível em: http://nides.ufrj. br/images/Imagens/programas/ SOLTEC/TecDesSocSol.pdf. Acesso em: 26 ago. 2019.

MARQUES, I. da C. Engenharias brasileiras e a recepção de fatos e artefatos. In: LIANZA, S.; ADDOR, F. (Org.). Tecnologia e desenvolvimento social e solidário. 1. ed. atual. Porto Alegre: Editora da UFRGS, 2011. p. 17-30. Disponível em: http://nides.ufrj.br/images/Imagens/programas/SOLTEC/TecDesSocSol. pdf. Acesso em: 26 ago. 2019.

OLIVEIRA FILHO, R.; LARICCHIA, C. R. Projeto Campo-Cidade e o curso de extensão em gestão e cooperação agroecológica. In: HENRIQUES, F. C. et al. Tecnologia para o desenvolvimento social: diálogos Nides. Marília: Lutas Anticapital, 2018. p. 245-269. Disponível em: http://nides.ufrj.br/images/ Imagens/programas/SOLTEC/Publicacoes/LivroComCapa_BaixaRes.pdf. Acesso em: 31 ago. 2019. 


тreceramanasesen | AMAZÔNIA Tecnologia Social:

Reflexões Teórico-Práticas no Mundo Contemporâneo

Este número temático da Revista Terceira Margem Amazônia está centrado na questão da Tecnologia Social em nossa região. Essa é uma área de estudos e práticas muito cara aos autores brasileiros e latino-americanos, pois foi nesse contexto sociogeográfico que toda a conceituação e concretização da tecnologia social surgiu. 